12, 501-504 (1997)

\title{
Ecstasy (MDMA), Amphetamine, and LSD: Comparative Mood Profiles in Recreational Polydrug Users
}

\author{
A. C. PARROTT* and M. STUART \\ Department of Psychology, University of East London, London E15 4LZ, UK
}

\begin{abstract}
Twenty-one recreational polydrug users (age range: 17-34 years), were recruited into the study using the 'snowball' technique (Solowij et al., 1992). All had used MDMA (3,4-methylenedioxymethamphetamine, or 'Ecstasy'), LSD (lysergic acid diethylamide), and amphetamine, on different occasions. They completed modified Profile of Mood States Questionnaires, to indicate their typical feeling states while on each drug. With three of the POMS factors, MDMA was intermediate between LSD and amphetamine, with feelings of energy, confidence and clearheadedness, highest under amphetamine, lowest on LSD, and intermediate after Ecstasy. However in other respects MDMA's mood profile was more unique, with significantly higher feelings of elation, agreeableness and composure, than the other two drugs. (C) 1997 John Wiley \& Sons, Ltd.
\end{abstract}

Hum. Psychopharmacol. Clin. Exp. 12; 501-504, 1997.

No. of Figures: 1. No. of Tables: 1. No. of References: 22.

KEY WORDS - Ecstasy; 3,4-methylenedioxymethamphetamine; MDMA; amphetamine, LSD; mood; POMS

\section{INTRODUCTION}

Methylenedioxymethamphetamine (3,4 MDMA) is a synthetic amphetamine derivative, with a broad spectrum of neurochemical effects. It is an indirect serotonergic agonist, but also displays binding affinity for dopaminergic and other neurotransmitter receptors (Solowij, 1993; McDowell and Kleber, 1994). While its dopaminergic agonist actions are similar to those of amphetamine, its serotonergic effects are closer to LSD. In behavioural terms, MDMA also displays similarities to both amphetamine and LSD. Its sympathomimetic and alerting effects are like those of amphetamine, whereas its propensity for intensifying sensory experience make it closer to LSD (McDowell and Kleber, 1994). Some authorities have therefore categorized 3,4-methylenedioxymethamphetamine as an hallucinogenic amphetamine, whereas others

${ }^{*}$ Correspondence to: A. C. Parrott, Department of Psychology, University of East London, London E15 4LZ, UK. Tel: 01815907722 ext. 4505 . Fax: 01818493697. have suggested that it is more unique, and should be placed within its own putative class (Nichols, 1986; Solowij et al., 1992). However there is a paucity of empirical data on the psychopharmacological changes generated by MDMA, particularly in relation to other drugs of abuse. The aim of this study was therefore to investigate the comparative mood profiles for MDMA, amphetamine and LSD, as described by recreational polydrug users.

\section{MATERIALS AND METHODS}

\section{Subjects}

Twenty-one unpaid subjects were obtained using the 'snowball' technique, where a small group of known drug users spread word of the study amongst friends and acquaintances (Solowij et al., 1992; Davison and Parrott, 1997). All had used amphetamine, MDMA, and LSD on different occasions. Their ages ranged from 17-34 years. 


\section{Profile of Mood States Questionnaire (POMS)}

This comprised a list of 72 mood adjectives, grouped into six bipolar mood factors (Lorr and McNair, 1980). The response format was modified to assess feeling state changes while on-drug (Parrott, 1996). The instructions were as follows: 'Below are some words which describe feelings and moods. Please tick one box for each word, indicating how you most feel ON or OFF Ecstasy. If you feel the SAME while on or off Ecstasy, please tick the SAME box'. For example:

Most like this when ON-ECSTASY

SAME on-and-off Ecstasy

Most like this when OFF-ECSTASY

Each response was scored: 0, 1, or 2. With 12 adjectives per mood subscale, a score of 12 indicated no mood change on-drug, and therefore represented baseline. The overall range of possible scores for each bipolar scale was 0-24. Three POMS questionnaires were completed, one for each drug type. Subjects were instructed that their responses for each questionnaire, should be based upon their personal experience with each type of drug. Anonymity and confidentiality were assured.

\section{RESULTS}

The ANOVA drug factor was highly significant for all six POMS mood factors (all comparisons $p<0.001)$ ). Duncan's multiple comparison tests were performed for each pair of drug conditions, and for each drug compared to baseline (Table 1). Amphetamine significantly affected three mood factors, with increased feelings of energy, elation, and confidence (Figure 1). MDMA affected four mood factors, with significantly higher feelings of energy, elation, agreeableness, and confidence. LSD led to significantly higher feelings of energy and elation, together with mental confusion, uncertainty, and anxiety (Figure 1). The MDMA

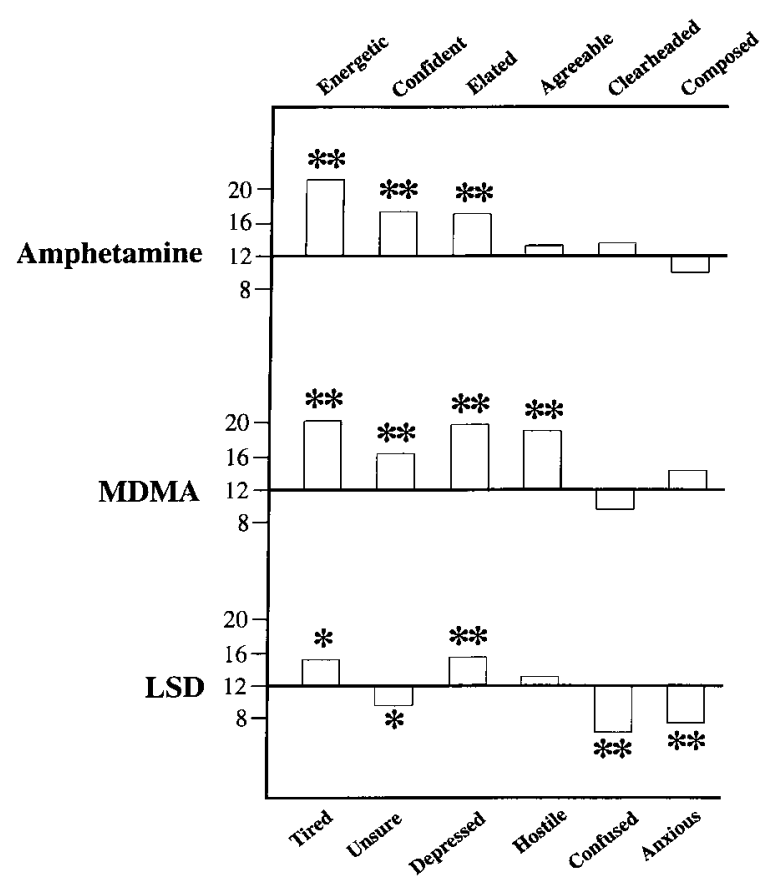

Figure 1. Profile of Mood States, as recalled by recreational polydrug users on MDMA, amphetamine, and LSD

mood scores were intermediate between amphetamine and LSD on three POMS factors: energetic/ tired, confident/unsure, and clearheaded/confused (Figure 1). While on the other three POMS factors, MDMA was not intermediate between amphetamine and LSD. Feelings of elation, agreeableness, and emotional composure, were all significantly higher under MDMA than amphetamine or LSD (all comparisons $p<0.01$; Table 1).

\section{DISCUSSION}

The mood profile for 3,4-methylenedioxymethamphetamine (MDMA), was of increased elation,

Table 1. Duncan multiple comparison tests between drug conditions

\begin{tabular}{lcccccc}
\hline POMS Mood State & AMP/BASE & MDMA/BASE & LSD/BASE & MDMA/AMP & MDMA/LSD & AMP/LSD \\
\hline Energetic-tired & $p<0.01$ & $p<0.01$ & $p<0.05$ & n.s. & $p<0.01$ & $p<0.01$ \\
Confident-uncertain & $p<0.01$ & $p<0.01$ & $p<0.05$ & n.s. & $p<0.01$ & $p<0.01$ \\
Clearheaded-confused & n.s. & n.s. & $p<0.01$ & $p<0.01$ & $p<0.05$ & $p<0.01$ \\
Elated-depressed & $p<0.01$ & $p<0.01$ & $p<0.01$ & $p<0.01$ & $p<0.01$ & n.s. \\
Agreeable-hostile & n.s. & $p<0.01$ & n.s. & $p<0.01$ & $p<0.01$ & n.s. \\
Composed-anxious & n.s. & n.s. & $p<0.01$ & $p<0.01$ & $p<0.01$ & $p<0.05$ \\
\hline
\end{tabular}

AMP, amphetamine; MDMA, 3,4-methylenedioxymethamphetamine (Ecstasy); LSD, lysergic acid diethylamide; BASE, baseline (drug free). 
agreeableness, energeticness and confidence (Figure 1). This was similar to previous reports. Solowij et al. (1992) noted increased feelings of energy, activation, euphoria, and confidence, in Australian MDMA users. Peroutka et al. (1988) noted feelings of happiness, euphoria, alertness and enhanced sensuality, in American college students. Davison and Parrott (1997) documented a profile of increased elation, agreeableness, energeticness and mental confusion, in British Ecstasy users. The above studies also described marked physiological changes, with increased heart rate, sweating and dehydration. These can easily lead to medical emergencies, particularly in the hot and crowded conditions of raves and dances. The confused person may dehydrate through hyperthermia, or overcompensate and drink too much water, thus lethally diluting their plasma electrolytes (Maxwell et al., 1994). The mood-elevating effects of MDMA are therefore not free from serious medical risks (Dowling et al., 1987; Henry et al., 1992; Lee, 1994; Maxwell et al., 1994; Series et al., 1994; Parrott, 1995).

Amphetamine demonstrated both alerting and euphoriant effects (Figure 1), following its agonist actions upon the reticular formation, and dopaminergic reward systems (Ashton, 1987). Most previous LSD research has focused upon its perceptual and cognitive effects, and its mood profile has rarely been studied. The current LSD data showed a mixture of beneficial and detrimental mood changes, with increased energy and elation, combined with feelings of uncertainty, confusion and anxiety (Figure 1). In comparative terms, MDMA was intermediate between amphetamine and LSD on three POMS factors: energeticness, confidence, and clearheadedness. Whereas on the other three POMS factors, MDMA produced significantly higher scores than both amphetamine and LSD (Figure 1; Table 1). Overall therefore, while the alerting effects of MDMA are broadly intermediate between amphetamine and LSD, its euphoriant properties seem more unique (Nichols, 1986; Liester et al., 1992; Solowij et al., 1992; Davison and Parrott, 1997).

It should be emphasized that subjects were asked to describe how then typically felt on each type of drug; yet all three drugs can generate unpleasant experiences. Solowij et al. (1992, p. 1169) reported that 28 per cent of their sample had suffered an: 'Acute bad reaction to MDMA such as paranoia, panic, loss of reality, loss of control, anxiety, and hallucinations'. Davison and Parrott
(1997) similarly noted that 25 per cent of their subjects had experienced at least one bad MDMA trip, due to: vomiting, paranoia, fear, panic, feeling immobile, confused thought, or thoughts of death (one subject now avoids all illicit drugs, following a particularly distressing MDMA experience). Prolonged psychiatric after-effects of MDMA have also been described (Lee, 1994; Maxwell et al., 1994; Series et al., 1994). Bad trips are a common occupational hazard of LSD, while amphetamine/cocaine abusers are renowned for their paranoia, and propensity for physical violence (Angrist. 1987).

Unpleasant mood states also occur on drug withdrawal, during neurochemical depletion. The after-effects of an amphetamine trip include feelings of fatigue, irritability, lassitude and depression. Similarly, MDMA trips are followed by feelings of lethargy, depression, irritability, insomnia, and paranoia, during serotonergic and dopaminergic depletion (Solowij et al., 1992; McDowell and Kleber, 1994). The mood changes after an LSD trip include lassitude and nervousness, together with cognitive and perceptual flashbacks. The long-term neurochemical effects of repeated drug use are also a matter of concern. Cognitive performance deficits have been demonstrated in regular MDMA users (Krystal et al., 1992; Parrott, 1997; Parrott et al., unpublished data), and the serotonergic depletion which accompanies regular MDMA use, has worrying implications for the future health of young drug users (Ricaurte and McCann, 1992; Solowij, 1993; McDowell and Kleber, 1994;

This study suffered from various methodological limitations. The data were based upon retrospective recall, so that selective memory biases may have affected subjects' reports. There was no control over what drugs had been taken (composition, purity, or strength), nor the environmental conditions (Zinberg, 1984). Despite these problems, the overall consistency of the current findings, and similarity to those described elsewhere (Peroutka et al., 1988; Liester et al., 1992; Solowij et al., 1992), provides support for their general construct validity (Parrott, 1991). Nevertheless, placebocontrolled MDMA trials would answer a number of crucial questions, if they were ethically sanctioned. Dose-response effects, time course and recovery profiles, acute and chronic tolerance, inter-subject variation, expectancy, and the influence of environmental factors, could all be usefully studied. 


\section{REFERENCES}

Angrist, B. (1987). Clinical effects of central nervous system stimulants: a selective update. In: Brain Reward Systems and Abuse, Engel, J. and Oreland, L. (Eds), Raven Press, New York.

Ashton, H. (1987). Brain Systems, Disorders, and Psychotropic Drugs. Oxford University Press, Oxford.

Davison, D. and Parrott, A. C. (1997). Ecstasy (MDMA) in recreational users: self-reported psychological and physiological effects. Human Psychopharmacology, 12, 221-226.

Dowling, G. P., McDonough, E. T. and Bost, R. O. (1987). 'Eve' and 'Ecstasy' - a report of five deaths associated with the use of MDEA and MDMA. Journal of the American Medical Association, 257, 1615-1617.

Henry, J. A., Jeffreys, K. J. and Dawling, S. (1992). Toxicity and deaths from 3,4-methylenedioxymethamphetamine ('ecstasy'). Lancet, 340, 384-387.

Krystal, J. H., Price, L. H., Opsahl, C., Ricaurte, G. A. and Heninger, G. R. (1992). Chronic 3,4-methylenedioxymethamphetamine (MDMA) use: effects on mood and neuropsychological function? American Journal of Drug and Alcohol Abuse, 18, 331-341.

Lee, J. W. Y. (1994). Catatonic stupor after 'ecstasy'. British Medical Journal, 310, 372-374.

Liester, M. B., Grob, C. S., Bravo, G. L. and Walsh, R. N. (1992). Phenomenology and sequelae of 3,4-methylenedioxymethamphetamine use. Journal of Nervous and Mental Disease, 180, 345-352.

Lorr, M. and McNair, D. (1980). Profile of Mood States: Bipolar Form. Educational and Industrial Testing Service, San Diego, California.

Maxwell, D. L., Polkey, M. I. and Henry, J. A. (1994). Hyponatraemia and catatonic stupor after taking 'ecstasy'. British Medical Journal, 307, 1399.

McDowell, D. M. and Kleber, H. D. (1994). MDMA: its history and pharmacology. Psychiatric Annals, 24, 127-130.
Nichols, D. E. (1986). Differences in the mechanism of action of MDMA, MBDB, and the classic hallucinogens. Identification of a new therapeutic class: entactogens. Journal of Psychoactive Drugs, 18, 305-318.

Parrott, A. C. (1991). Performance tests in human psychopharmacology (3): construct validity and test interpretation. Human Psychopharmacology, 6, 197-207.

Parrott, A. C. (1995). Wobble, rave, inhale, or crave? Report on the British Psychological Society Annual Conference Symposium: 'Drugs of Use and Abuse'. Journal of Psychopharmacology, 9, 390-391.

Parrott, A. C. (1996). Cannabis mood effects and smoking motives in regular users. British Psychological Society Proceedings, 4, 93.

Parrott, A. C. (1997). The psychobiology of MDMA or 'Ecstacy'. Journal of Psychopharmacology, (in press).

Parrott, A. C., Lees, A., Wesnes, K., Garnham, N. J. and Jones, M. Cognitive deficits in recreational users of MDMA or 'Ecstasy'. (Submitted).

Peroutka, S. J., Newman, H. and Harris, H. (1988). Subjective effects of 3,4-methylenedioxymethamphetamine in recreational users.

Ricaurte, G. A., and McCann, U. D. (1992). Neurotoxic amphetamine analogues: effects in monkeys and implications for humans. Annals of the New York Academy of Sciences, 648, 371-382.

Series, H., Boeles, S., Dorkins, E. and Peveler, R. (1994). Psychiatric complications of 'Ecstasy' use. Journal of Psychopharmacology, 8, 60-61.

Solowij, N. (1993). Ecstasy (3,4-methylenedioxymethamphetamine). Current Opinion in Psychiatry, 6, 411-415.

Solowij, N., Hall, W. and Lee, N. (1992). Recreational MDMA use in Sydney: a profile of ecstasy users and their experience with the drug. British Journal of Addiction. 87, 1161-1172.

Zinberg, N. (1984). Drug, Set and Setting. Yale University Press, Connecticut, USA. 